Cos

\title{
limiar
}

VOL.1 - $N^{\circ} 1-2^{\circ}$ SEMESTRE 2013

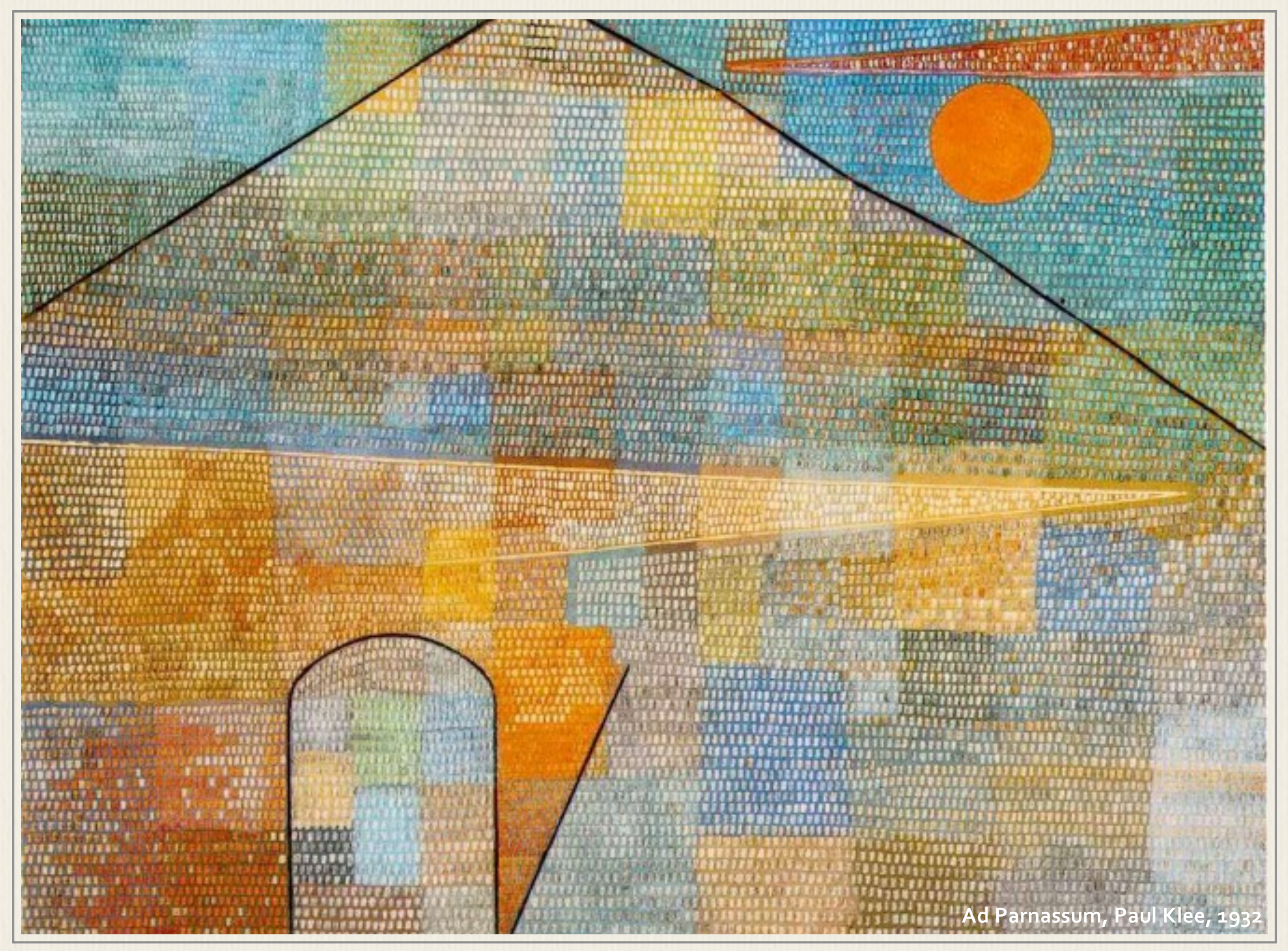




\section{A MÚSICA COMO ARTE NÃO FIGURATIVA}

Sidnei de Oliveira

Doutorando IFCH|UNICAMP

Bolsista FAPESP

Os olhares não artísticos não são capazes de penetrar com complacência os abismos dionisíacos; tal é maneira com que Nietzsche vê os gregos que não absorvem a tragédia, mais especificamente Sócrates, que enxerga na tragédia uma enorme confusão, ou seja, efeito sem causa e causa sem efeito. E ainda os que possuem mentes sensíveis, aqueles que não são capazes de se manterem firmes em relação ao princípio de causalidade, isto é, crianças e ignorantes, que enxergam o teatro como uma pedagogia da formação, Sócrates julga serem apenas mentes impressionadas e não filosóficas. Sendo assim, para Sócrates a tragédia não diz a verdade e, por este motivo, não há uma ligação com o filósofo.

Tanto Platão como a tragédia caracterizam-se pelo mesmo procedimento, a saber, a união da narrativa, da lírica, do drama, da prosa e da poesia. Então, neste procedimento, podemos incluir Wagner, pois assim como a tragédia, o drama wagneriano também absorve cada uma de tais artes. Enquanto Platão concentra todos os gêneros narrativos e, inclusive, artísticos, Wagner com a sua obra de arte total realiza exatamente a mesma função, a de consubstanciar todas as formas artísticas na ideia de drama musical. De fato, todo gênero trágico nada mais é do que o resultado de uma síntese genial das artes figurativas, das quais a poesia vive seu apogeu ao lado das artes tonais, em que a música é o ápice. Sendo a filosofia uma tentativa de conciliar a pulsão teórica com a pulsão artística, é possível que esta arte renasça sob o mesmo espírito da tragédia com Wagner e sua Gesamtkunswerk. Para Nietzsche, essa é a verdadeira cultura a qual os alemães não vivenciavam.

Neste mesmo capítulo 14, Nietzsche intui certo otimismo no pensamento socrático, a lógica e a dialética na intuição das ideias. O olhar de Sócrates vê na tragédia uma banalidade porque não é um olhar artístico. Assim, Eurípedes é o trágico que vai reformar a tragédia, primeiramente a função do coro e depois introduzir o deus ex machina, que nas palavras de Nietzsche nada mais é que "justiça poética”.

1. Friedrich Nietzsche. O Nascimento da Tragédia ou Helenismo e Pessimismo. São Paulo: Companhia das Letras, 2001, p. 89.
Como se afigura agora esse novo mundo cênico socrático otimista em face do coro e mesmo de todo o substrato musical-dionisíaco da tragédia? Como algo acidental, como uma reminiscência possível também dispensável da origem da tragédia, ao passo que nós já vimos, ao invés, que o coro só pode ser entendido como causa primeira da tragédia e do trágico em geral. ${ }^{1}$ 
2. Platão. Platão - Diálogos. São Paulo: Nova Cultural, 1999. p. 120.

3. Friedrich Nietzsche. O Nascimento da Tragédia ou Helenismo e Pessimismo. São Paulo: Companhia das Letras, 2001, p. 91.

4. Arthur Schopenhauer. O mundo como vontade e como representação. São Paulo: UNESP, 2005, pp. 43-49.
O coro é propriamente o substrato musical da tragédia, assim como acontece na canção popular, isto é, uma comunidade consumida, a realização do êxtase, da embriaguez, a fusão da personalidade individual, do eu no todo, é o estar fora de si. A possessão dionisíaca acontece no coro através de uma força transcendente, de uma fusão mística de todos aqueles que celebram na comunhão do deus Dioniso, é a massa que canta e entoa os ditirambos.

Nietzsche ressalta o Sócrates musicante, momento este que surgiu enquanto ele esperava a hora de sua morte na prisão. Segundo Platão, Sócrates conta que certa aparição em seus sonhos continuava a dizer "exercita-te na música", 2 o que para ele não passava de uma música simplesmente vulgar e popular, pois em seu entendimento ele sempre fez música, já que considerava a filosofia a verdadeira música, a música por excelência. Ao mesmo tempo em que Sócrates tinha este conhecimento, sabia que o daimon era aquele que fazia a transição e a passagem entre os deuses e os mortais, portanto, até os dias de sua prisão, fazer música era um dever aindả não realizado. Para desafogar a sua consciência moral Sócrates decide compor a música popular e tão depreciada por ele. Para Nietzsche, esta reação deuse por Sócrates não conseguir perceber a beleza da música e, por este motivo, a apropriação do bárbaro referindo-se a Sócrates.

O que o impeliu a tais exercícios foi algo parecido à voz admonitória do daimon, foi a sua percepção apolínea de que não compreendia, qual um rei bárbaro, uma nobre imagem de um deus e corria assim o perigo de ofender sua divindade - por sua compreensão. Aquela palavra da socrática aparição onírica é o único sinal de uma dúvida de sua parte sobre os limites da natureza lógica: será - assim devia ele perguntar-se - que não compreensível para mim não é também, desde logo, o incompreensível? Será que não existe um reino da sabedoria, do qual a lógica está proscrita? Será que a arte não é até um correlativo necessário e um complemento da ciência?3

Quando Nietzsche lê a passagem no Fédon sobre a música, identifica o Sócrates que percebeu os limites da natureza lógica e o discernimento propriamente socrático de que a natureza lógica não tem fronteiras, logo, o pensamento é capaz de desvendar todos os limites do universo desde que seja conduzido pela causalidade. Desta forma, não existe nenhum limite intransponível para o conhecimento ainda que saber signifique penetrar cada vez mais e de maneira infinita no âmbito do desconhecido Assim, tudo aquilo que cai sobre o princípio de razão, tudo aquilo que podemos conhecer ou ser pensado na categoria do entendimento, é limitado e, deste modo, não podemos conhecer nada que não seja dado pela natureza, "o que existe para o conhecimento, portanto o mundo inteiro, é // tão somente objeto em relação ao sujeito, intuição de quem intui, numa palavra, representação [...] o mundo como representação submetido ao princípio de razão".4 
O nosso conhecimento científico limita-se àquilo que não é essencial; a coisa em si, então, não podemos conhecer de nenhuma maneira ou apenas por um gênero de conhecimento não específico, ou seja, por uma espécie de representação que não segue o princípio de razão suficiente. Para Schopenhauer, este conhecimento é metafísico, uma intuição, uma apreensão direta e imediata do incondicionado, a Vontade, este é o ponto onde a ciência não é capaz de chegar devido aos seus limites.

Em Nietzsche, tudo aquilo que não podemos compreender ou intuir, desde que não seja através da forma do conhecimento causal, é precisamente a arte, pois não é algo menor em relação ao conhecimento intelectual, mas sim um complemento indispensável. Podemos citar o exemplo da análise da Nona Sinfonia de Beethoven, pois a arte de compor é algo incompreensível pelo "ouvinte ou espectador", daí a necessidade da compreensão através da partitura, pois só assim é possível entender o processo depois da obra concluída, e não é por esta circunstância que seremos capazes de alcançar a genialidade de Beethoven. Segundo Nietzsche, a ação que a composição é capaz de gerar em seu criador foi a mesma experiência que Sócrates teve ao compor um proêmio a Apolo, pois não há uma oposição absoluta entre arte e ciência. Portanto, no ponto de vista da integridade da vida, nós precisamos tanto da aparência quanto da experiência, da verdade e da mentira, esta dualidade que decorre até o momento em que percebemos a união de ambas as potências.

Esse diálogo que aparece no Fédon é para Nietzsche de grande importância, pois sustenta que a arte não representa o falso e a ciência não é a pura verdade, já que as duas coisas são igualmente necessárias, mesmo a arte sendo uma verdade metafísica. A partir de agora é possível visualizar o Sócrates musicante, pois ele teria realizado este processo artístico ao se deixar seduzir pelo daimon e, assim, fazer a arte que é o coração de todas as artes, a música. Para Nietzsche, o Sócrates musicante é o verdadeiro Sócrates.

Se Nietzsche apropria-se de Schopenhauer e de Platão para mostrar a importância da música como verdade metafísica, Wagner faz o mesmo processo ao ouvir e tentar desvelar o homem Beethoven e sua obra máxima, a Nona Sinfonia. Wagner tem Beethoven como o exemplo mais próximo possível da natureza humana imergida em seu interior porque é quando fica surdo que compõe o verdadeiro Beethoven. Este é, para Wagner, a essência da música alemã, pois nada mais lhe tira a atenção, é o processo do gênio compositor nas últimas consequências e, ao perceber isso, Wagner vai buscar a sua verdade representada em seus dramas através dos mitos germânicos.

Quando lê o Beethoven, Nietzsche evidencia da mesma forma o sentido da música como uma arte que sustenta as demais em seus devidos lugares, pois a música não promove a excitação do agrado pelas belas formas, como as artes figurativas. Mesmo que tal excitação esteja presente como acontece na tragédia, a primordial diferença está na música que é o princípio desta ação, assim como é a Ideia imediata da vida. Nietzsche, após a leitura de Beethoven, declara a importância e ao mesmo tempo a necessidade de se aproximar da tragédia grega, já que, segundo ele, tomou conhecimento sobre esta enorme contraposição estética com Wagner. 
5. Friedrich Nietzsche. O Nascimento da Tragédia ou Helenismo e Pessimismo. São Paulo: Companhia das Letras, 2001, pp. 97-98.
O mais importante de toda a estética, com o qual somente ela começa um sentido mais sério, Richard Wagner, para corroborar-lhe a eterna verdade, imprimiu o seu selo, quando no Beethoven estabelece que a música deve ser medida segundo princípios estéticos completamente diferente dos de todas as artes figurativas e, desde logo, não segundo a categoria da beleza: ainda que uma estética errônea, pela mão de um arte extraviada e degenerada, tenha se habituado a exigir da música, a partir daquele conceito de beleza vigente no mundo figurativo, um efeito parecido ao das obras de arte figurativa, a saber, a excitação do agrado pelas belas formas. Após tomar conhecimento dessa enorme contraposição, senti uma necessidade de me aproximar da essência da tragédia grega e com isso da mais profunda revelação do gênio helênico; pois só então julguei dominar a magia requerida para, mais além da fraseologia de nossa estética usual, poder colocar-me de maneira viva e concreta o problema primordial da tragédia: como o que me foi dado lançar uma olhada tão estranhamente peculiar no helênico que tinha de me parecer como se a nossa ciência clássico-helênica, tão orgulhosa em seu comportamento, no principal haja sabido apascentar-se até agora somente com jogos de sombras e com exterioridades. ${ }^{5}$

Mesmo que Nietzsche apresente em O Nascimento da Tragédia determinada independência na sua filosofia quando direciona seu pensamento para a Grécia Antiga, pois é o que prevalece quando discute a questão estética, a origem e a cultura da música popular; ele próprio não nega que Wagner e Schopenhauer foram alicerces necessários para o seu primeiro livro. Devemos ler O Nascimento como se não soubéssemos do afastamento que houve entre Wagner e Nietzsche. Desta forma, compreenderemos o envolvimento destes três nomes que para nós tiveram grande importância na filosofia da música: Schopenhauer por elevar a música à arte suprema; Wagner por absorver esta mesma essência da música e, juntamente com a filosofia schopenhaueriana, inovar seu drama musical; por último Nietzsche que, para chegar ao objetivo estético apresentado em seu livro, assimilou cada aspecto levantado por Schopenhauer e Wagner. Oswaldo Giacoia aponta questões importantes que envolvem o primeiro livro de Nietzsche.

De um ponto de vista genérico, pode-se afirmar que a questão central da filosofia do jovem Nietzsche está ligada ao destino da arte e da cultura no mundo moderno [...] influenciado pela metafísica da vontade de Schopenhauer [...] e a teoria da arte de Richard Wagner. Este também se inspirou em Schopenhauer, acreditando que a música seria a mais adequada forma de manifestação daquela força criadora do mundo, a Vontade. Tomando Wagner e Schopenhauer como seus aliados, Nietzsche empreende uma crítica radical das tendências culturais dominantes em seu tempo, caracterizadas por uma confiança ingênua nas ideias de evolução e progresso lógico ou natural, no curso dos quais a humanidade teria alcançado um estágio de desenvolvimento em que estaria em condições de, humanizando a natureza e racionalizando a sociedade, aproximar-se do ideal da felicidade universal. ${ }^{6}$ 
7. Friedrich Nietzsche. O Nascimento da Tragédia ou Helenismo e Pessimismo. São Paulo: Companhia das Letras, 2001, p.130.
Que Nietzsche leu os escritos de Wagner não é contestável, porém ele escreveu seu primeiro livro esperando que Wagner também refletisse sobre os vários pontos levantados em $O$ Nascimento da Tragédia. Sabendo que Wagner elaborou seus libretos com base nos mitos germânicos, somados com as leituras de Schopenhauer, Nietzsche dedicaria a atenção necessária a sua música e, assim, esclarece pontos importantes e cuidadosos ao amigo, "Que o amigo atento se represente, segundo as suas experiências, o efeito de uma verdadeira tragédia musical, pura e sem imisção. Penso ter descrito de tal forma o fenômeno [Phänomen] deste efeito, por ambos os lados, que este amigo saberá agora explicar as suas próprias experiências".7 Nietzsche refere-se ao movimento que há no mito, e como a música pode infiltrar mais a fundo as figuras em movimento, ela é a verdadeira vida no mito trágico, pois enquanto o mito encontra-se apenas no domínio apolíneo, a contemplação é bela e plástica, é a justificação do mundo através da aparência. O que Nietzsche quer apresentar a Wagner é simplesmente o surgimento dionisíaco no ato, algo que faz enxergar profundamente o que não seria possível sem a música, a excitação apolínea pela aparição sonora dionisíaca, ou seja, Wagner deve compreender e explorar esta união em seu drama.

Com isso é possível observar que Nietzsche conhece a dimensão da música na tragédia e vê no drama wagneriano a relação desta mesma música com o ato cênico e a palavra. O terceiro ato de Tristão e Isolda é para Nietzsche o exemplo da música primordial, isto é, a maneira possível de absorver a tragédia ali apresentada. Este é o preciso momento em que Nietzsche reconhece o trabalho responsável de Wagner em seu drama: “A velha melodia, porque ela me desperta?”. Abaixo a melodia a que Tristão se refere sendo tocada sozinha pelo Corne Inglês:

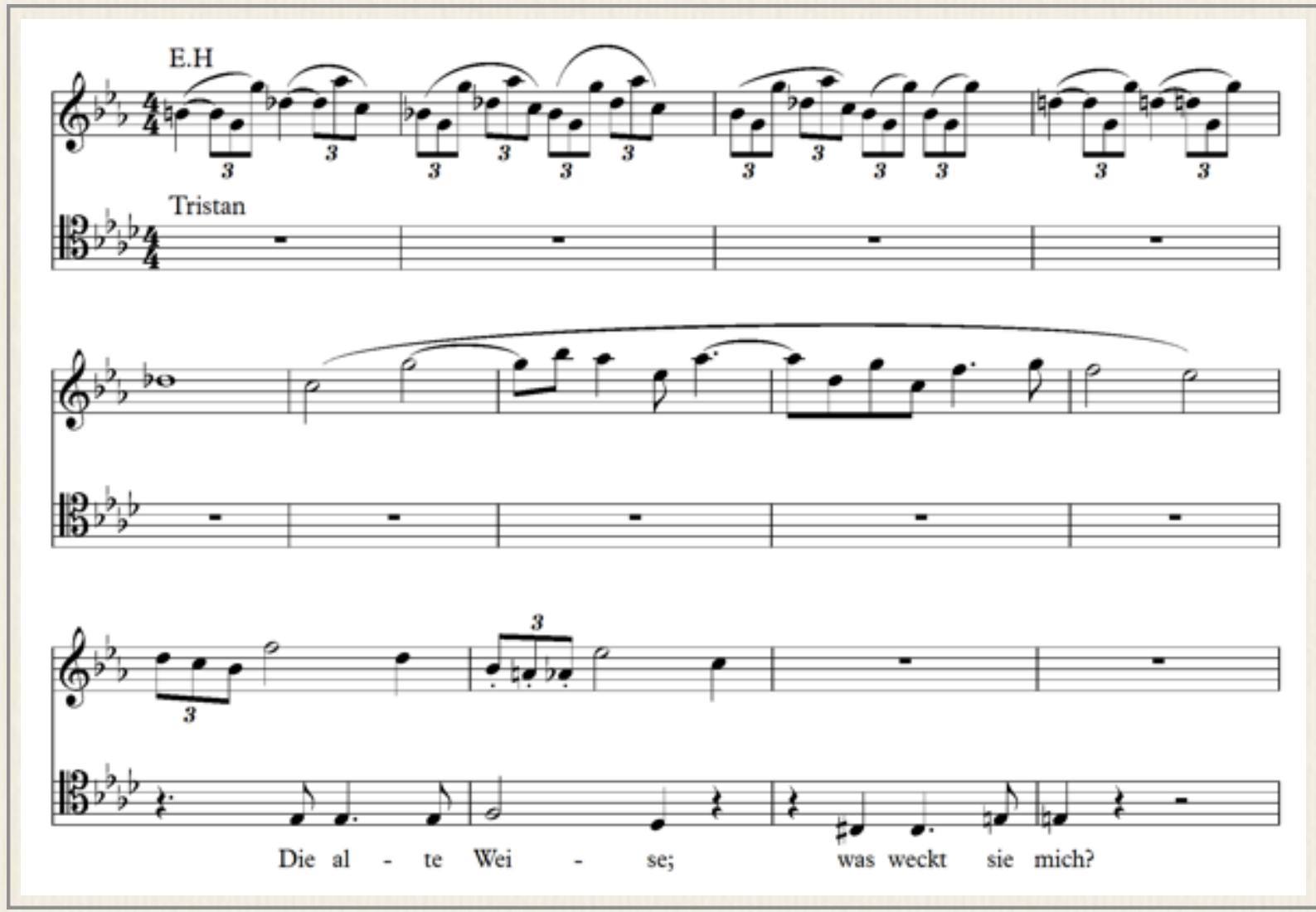

Richard Wagner. Partitura de Tristão und Isolde. Ed. Edwin F. Kalmus, New York, n.d. (after 1933).

Este ponto anunciado por Nietzsche mostra exatamente a ligação da arte plástica apolínea com a música dionisíaca, isto é, a legitimação da obra de arte total. 
Nietzsche, a partir deste trecho, mostra que enxergamos a ação de Tristão, embora isso não passe de uma ilusão apolínea, já que, com a música, é possível a imersão na representação da ideia no palco apresentado. Para Nietzsche, "No fundo, a relação da música com o drama é precisamente a inversa: a música é a autêntica Ideia do mundo, o drama é somente um reflexo, uma silhueta isolada desta Ideia". 8

Sendo Tristão e Isolda um marco no drama wagneriano, já que teve uma mudança na composição e também no libreto influenciado pelas leituras de Schopenhauer, é possível entender em uma carta de Wagner a Liszt, o que o compositor tinha em mente sobre a elaboração e composição do seu drama.

9. Wagner. 1854, apud Ramar da Costa Nunes. Óperas Românticas e Dramas Musicais de Richard Wagner. Rio de Janeiro: R.C. Nunes. 2003, p. 11.

10. Ernani Chaves. "Ética e estética em Nietzsche: Crítica da moral da compaixão como crítica aos efeitos catárticos da arte". Revista Ethica. Rio de Janeiro. p. 50.
Porque eu nunca experimentei a verdadeira felicidade do amor, quero levantar um verdadeiro monumento ao mais belo de todos os sonhos, no qual, do começo ao fim, esse amor possa, por um só momento, ser suficiente para satisfazer os amantes [...] Minhas obras não são senão atos musicais que se tornam visíveis [...] É à arte a quem devo as constantes contradições de meu ser. ${ }^{9}$

É a partir de pensamentos como este, somados a sua genialidade musical, aos mitos germânicos que desenvolvia em seus dramas e à filosofia de Schopenhauer, que Wagner mudaria a recepção musical da Alemanha e, por conseguinte, a da Europa como um todo. Quando Nietzsche percebe que existe uma possibilidade de tal acontecimento, nomeia como ouvinte estético aquele capaz de ocupar o lugar do ouvinte crítico que dominava o século XIX. Portanto, somente o ouvinte estético conseguiria sentir realmente a obra wagneriana, pois compreenderia o mito apresentado nesta obra de arte total. Para Ernani Chaves, "O 'ouvinte excitável esteticamente' coloca em primeiro plano a força do mito para a fantasia artística e, principalmente, a possibilidade de se pensar a cultura, não mais fundada em um 'costume originário/primordial' (Ursitz) arraigado e religioso". ${ }^{10}$ Nietzsche vai comparar este prazer estético do entendimento do mito com uma dissonância musical, logo, a música ao lado do mundo é a justificativa de um mundo como fenômeno estético.

Nietzsche espera, de uma aliança contraída entre a tradição espiritual da filosofia alemã, simbolizada em Schopenhauer, e o poder irresistível da música alemã, simbolizada em Wagner, um renascimento do espírito trágico, que daria novo alento e autenticidade a uma cultura depauperada, que vive no consumo da cultura de todos os povos e épocas numa confusão bárbara de todos os estilos; uma cultura consumida pela erudição vazia, desprovida de identidade própria e de vitalidade. Do mesmo modo que, na Grécia, foi a partir do solo sagrado da arte - especialmente da tragédia nascida do espírito da música - que floresceu o melhor da cultura helênica, assim seria também, na Alemanha, o espírito da música de Wagner o que despertaria o vigor originário dos mitos germânicos, fazendo renascer a cultura trágica alemã e, com ela, como farol para os outros povos da Europa, as possibilidades de 
elevar o ser humano bem acima do que ele já realizara ao longo de sua história. ${ }^{11}$

Esta questão levantada por Oswaldo Giacoia é a aliança que Nietzsche espera entre a filosofia estética de Schopenhauer, a música de Wagner e a sua própria filosofia apresentada em $O$ Nascimento da Tragédia, em vista do resgate de uma Alemanha que viesse a renascer através do espírito da música. 